\title{
ENTREVISTA COM BILL MAURER
}

\section{Patrícia Kunrath Silva*}

\section{Universidade Federal do Rio Grande do Sul - Brasil}

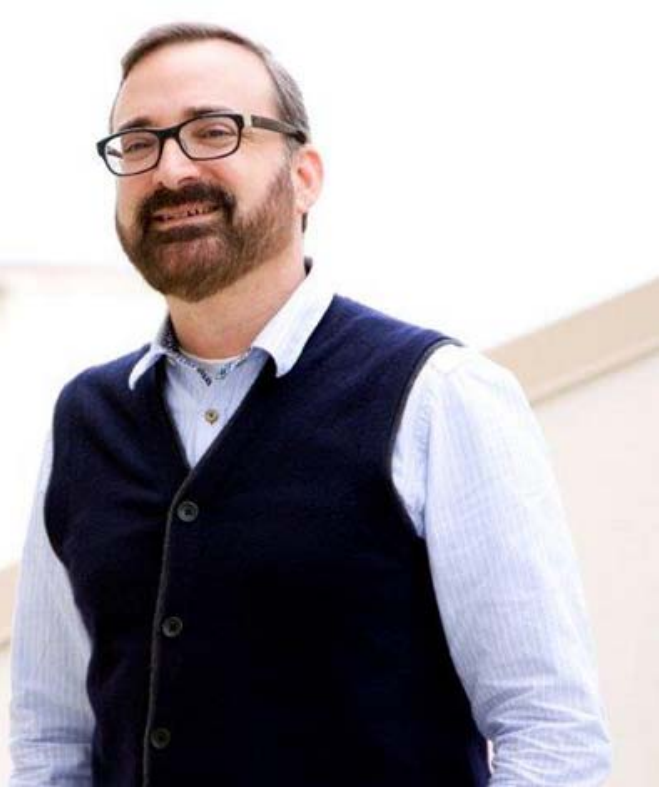

Bill Maurer (foto: Kristen Salisbury).

* Doutoranda em Antropologia Social. Contato: patricia.kunrath@gmail.com.

Horizontes Antropológicos, Porto Alegre, ano 22, n. 45, p. 395-408, jan./jun. 2016 http://dx.doi.org/10.1590/S0104-71832016000100015 
Bill Maurer é um importante antropólogo norte-americano, professor de Antropologia, Direito e Criminologia, Direito e Sociedade; pró-reitor de Ciências Sociais e diretor do Instituto para Inclusão Financeira, Dinheiro e Tecnologia (Institute for Money, Technology and Financial Inclusion - IMTFI) na Universidade da Califórnia em Irvine. Entre seus interesses de pesquisa estão questões de dinheiro e moral, finanças e moedas alternativas, bancos islâmicos, globalização e governamentalidade, atentando para antropologias da economia e da política.

\section{Entrevista}

Você iniciou seus estudos, focado em antropologia e estudos de gênero nos anos 1980, correto? Você poderia nos falar de sua trajetória acadêmica e profissional? Você chegou a um ponto específico em que seus interesses se deslocaram para dinheiro e finanças ou você sempre se interessou pelo assunto?

Você tem razão. Essa mudança aconteceu devido à minha tese de doutorado. Para a minha tese, eu realmente queria entender as dinâmicas e mudanças de família e parentesco no Caribe e, especificamente, o que estava acontecendo com as famílias quando as pessoas nas Antilhas [West Indies] migravam para outras ilhas do Caribe em vez de migrar para as cidades globais do Norte. Nos anos 1970 e 1980 havia intensa migração transnacional entre o Caribe e Londres, Toronto e a cidade de Nova Iorque. Eu estava começando a ver, baseado em trabalho de campo que eu havia feito na ilha de Dominica nas Antilhas e mais tarde nas Ilhas Virgens Britânicas, que havia muita migração interna no Caribe. Pessoas circulando, mas em circuitos que as mantinham dentro da região em vez de saírem para as grandes cidades do Norte, e eu fiquei perplexo com isso. Por que isso estava acontecendo? O que estava acontecendo? Então, fiz meu primeiro trabalho de campo para minha tese de doutorado nas Ilhas Virgens Britânicas, que se haviam tornado um ponto de destino para muitos destes migrantes caribenhos. Mesmo na formulação desse projeto, se você olhar meus antigos pedidos de financiamento, tudo era focado em imigração e cidadania e, em particular, na forma como as Ilhas Virgens Britânicas estavam negando cidadania aos filhos de imigrantes. As pessoas migravam de ilhas como São Cristóvão e Névis, chegavam nas Ilhas Virgens 
Britânicas (IVB), tinham filhos, mas os filhos ficavam basicamente sem nacionalidade, pois as IVB não lhes concediam cidadania.

Eu estava interessado em como isso estava funcionando, especialmente porque essas pessoas eram descendentes de afro-caribenhos. Todos eles eram, inicialmente, parte da colônia britânica nas Ilhas Leeward, uma grande colônia, e ainda assim aqui estávamos diante da emergência de novas formas de diferença e distinção, devido à forma que a imigração estava assumindo. Então, nada sobre dinheiro... mas nas IVB, para onde você olhar há sinais de negócios e serviços financeiros offshore [paraísos fiscais]. Há firmas de consultoria, bancos, companhias de trust e firmas de direito e contabilidade. E quanto mais eu mexia na história da política de imigração, mais eu via que o que estava realmente acontecendo nos anos 1980, quando eles reestruturaram sua política de imigração, é que estavam excluindo imigrantes, mas também provendo assim uma forma de proteger os britânicos. As mesmas políticas que excluíam os imigrantes de um completo pertencimento também excluíam os britânicos de um completo pertencimento, mas os britânicos não queriam pertencer politicamente, eles apenas queriam esconder seu dinheiro lá, certo? Então a questão da imigração ajudou a levantar a questão dos paraísos fiscais e ambos estão intimamente interligados. Isso foi quando comecei a pensar "ok, eu preciso entender finanças, eu preciso entender dinheiro global”. Na minha tese, que se tornou meu primeiro livro, apenas um capítulo lida com o setor de serviços financeiros, todo o resto é sobre gênero, parentesco, família e imigração. No entanto, após terminar esse livro me dei conta de que eu precisava entender o setor de serviços financeiros offshore.

Meu próximo grande projeto foi todo sobre isso e foi realmente olhando para finanças offshore que me interessei por bancos islâmicos. Pois um dos maiores locais de finanças e bancos islâmicos do mundo nos anos 1990 era o Caribe, uma vez que o sistema bancário islâmico não permite juros, então o que você faz é depositar o seu dinheiro em uma conta, mas ele é usado e aplicado conjuntamente com o dinheiro de outras pessoas e colocado em empreendimentos produtivos, então você tem um lucro como teria em um fundo mútuo. Antes dos anos 2000, esse tipo de mistura de banco de correntistas e banco de investimentos era ilegal no Norte global, então o único lugar em que se podia fazer isso era nos paraísos fiscais. Então, novamente, eu estava perplexo. "Por que há esses bancos islâmicos nas IVB? Como eu entendo isso?” E “isso” eram os bancos islâmicos, o que me levou a pensar 
mesmo em moedas alternativas, pois meus primeiros sujeitos entrevistados, que eram profissionais de finanças islâmicas aqui no sul da Califórnia, me dirigiram a ir e a aprender mais sobre moedas alternativas. Essas pessoas de bancos islâmicos estavam muito interessadas em experimentos que estavam acontecendo em comunidades ao redor do mundo, especialmente nos Estados Unidos, no Reino Unido, no Canadá, na Nova Zelândia e na Austrália. Eles estavam tentando criar dinheiro que não dependesse de juros e eles mesmo, banqueiros islâmicos, estavam lendo a literatura sobre moedas alternativas e a entrelaçando com suas próprias ideias. Eu lembro de fazer uma entrevista, na verdade aqui perto em Pasadena, onde um profissional das finanças islâmicas muito proeminente me disse "você deveria fazer uma conferência para todos nós birutas do dinheiro, pessoas que estão pensando de forma esquisita sobre dinheiro, e você deveria me convidar, e convidar Paul Glover, que fundou o Ithaca Hours, etc.....”. Então eu encaminhei um pedido de financiamento para a National Science Foundation [Fundação Nacional de Ciência] para explorar essa interconexão entre bancos islâmicos e moedas alternativas. Isso me levou ao próximo livro, Mutual life, limited, ${ }^{1}$ mas também me vislumbrou o problema do dinheiro e fez do dinheiro e finanças meu principal interesse de pesquisa, que tem sido este deste então.

Quais são as maiores influências no seu trabalho? Em termos de teoria, quais autores clássicos ou contemporâneos mais influenciaram o seu pensamento e como?

Eu acho que na antropologia as maiores influências que tive foram de antropólogas feministas como Jane Collier, que foi minha orientadora, e Michelle Rosaldo em particular. Mas também pessoas como Jane Guyer e Keith Hart, Viviana Zelizer na sociologia, que também trabalham com dinheiro e que também - especialmente Guyer e Hart, à medida que os fui conhecendo pessoalmente - me permitiram desenvolver o tipo de pensamento que eu queria e me deram muito apoio ao longo do caminho. E outra pessoa que me deu muito apoio foi Nigel Thrift, o geógrafo. Eu sempre sinto que essa geração mais antiga me permitiu fazer o tipo de trabalho que fiz. Eles me deram cobertura,

1 Cf. Maurer (2005). 
porque eu queria explorar mais e torná-lo legítimo. Também em termos de teoria devo muito ao trabalho de J. K. Gibson-Graham, que são as geógrafas feministas que escrevem juntas sob um nome. Elas realmente me ajudaram a pensar a noção de economia plural e diversa e a partir delas venho explorando, mais recentemente - nos últimos cinco anos eu diria ou talvez sete anos - o pragmatismo americano, que pensa as noções de pluralidade e multiplicidade em formas que derivam de engajamentos com Darwin no século XIX, mas que se transformaram no início do século XX. Deleuze também tem sido uma inspiração importante para mim desde o início, bem como o trabalho de Marilyn Strathern. Deleuze para mim é a Strathern filosófica e Strathern é o Deleuze antropológico em termos de trazer à tona todas essas relações e linhas em vez de pontos, então essas são provavelmente as grandes influências.

No seu artigo de 2006 "The anthropology of money"2 você presta atenção no papel social e significados do dinheiro, bem como nas dimensões performativas e semióticas das finanças. Em relação às discussões sobre "ficções do dinheiro", autores como Viviana Zelizer, Keith Hart e George Simmel - em variadas perspectivas - se posicionam e argumentam contra a ficção do dinheiro como descolado da vida social e às vezes oscilam entre abordagens críticas e outras mais otimistas em relação ao papel do dinheiro na sociedade. Como você posiciona seu trabalho acerca de dinheiro e finanças nessas discussões?

Eu diria que estou menos interessado em adotar uma posição particular sobre dinheiro do que estou em explorar empiricamente como as pessoas estão fazendo dinheiro. Eu vejo dinheiro como um verbo e não apenas como uma coisa. Então como as pessoas o fazem? E aqui acho que estou provavelmente mais próximo de alguém como Jane Guyer, que também está pensando sobre esses tipos de repertórios performativos do dinheiro. Pois eu acho que para mim as questões "[o dinheiro] é mais ou menos social, é mais ou menos desconectado, abstrai, faz isso ou aquilo...”, para mim [o dinheiro] faz todas essas coisas, então a questão a ser colocada é “como, quando e por que ele está sendo performado de certa forma. Como as pessoas o estão fazendo?”

2 Cf. Maurer (2006a). 
Em termos de finanças você trabalhou com bancos islâmicos prestando atenção às dimensões sociais que vão além das críticas ao pensamento econômico racional. Você poderia nos falar um pouco mais sobre essa experiência de pesquisa, campo e o seu trabalho com números indo além da mensuração e abstração?

Eu tinha este outro pequeno livro, Islamic mortgages, ${ }^{3}$ que ganhou forma, pois, enquanto eu fazia a maior parte da minha pesquisa em bancos islâmicos, o setor de hipotecas islâmicas realmente se desenvolvia nos Estados Unidos e eu as achei peculiares e fascinantes, porque quanto mais você olhava para uma, mais se parecia com uma hipoteca convencional, certo? Mas a forma como as pessoas a articulavam e a forma como as pessoas entendiam os números que estavam sendo colocados em seus produtos e em suas tabelas de amortização, a forma como você vai quitando, parece que com o tempo ia carregando significados tão distintos e ia sendo informada por uma filosofia tão diferente e assim eu passei a levar realmente a sério que a prática dos números significava algo. Você não podia olhar apenas para os números em si, você tinha que olhar como eles estavam sendo colocados como partes de argumentos maiores em discussões e levar esses argumentos a sério. Então mesmo se parece para mim uma hipoteca normal com juros, isso é como parece para mim, e é como parece para eles também, mas eles também conseguiam dar a ela uma outra série de vinculações e circundá-la com um outro tipo de filosofia que anima diferentes questões. Questões relacionadas à moralidade, especificamente. Há um pensamento bastante profundo que é colocado nisso por parte das pessoas desenvolvendo essas coisas, que tem a ver com a unidade de Deus, com a posição teológica sobre o que são os números, o que é o dinheiro, que números não necessariamente apenas quantificam coisas no mundo, mas também apontam para uma espécie de essência divina a qual nunca alcançamos, mas que podemos tentar nos aproximar.

Você também trabalhou com finanças alternativas, uma discussão que no Brasil chama atenção para a economia solidária e redes de cooperativas, por exemplo, que recebem críticas quando se encontram

3 Cf. Maurer (2006b). 
tecnologias financeiras e bancárias. Qual é a sua abordagem ao sentido de finanças “alternativas" e como o trabalho dos antropólogos pode estar interligado com as práticas cotidianas das pessoas?

Essa é uma pergunta muito boa. É uma pergunta central. Eu sempre penso... Eu acho que há um problema quando ativistas ou intelectuais imaginam o alternativo como algo totalmente diferente: "O sistema é uma droga, então eu vou ficar fora do sistema.” Bem, ao dizer isso você já está atribuindo ao sistema uma enorme estabilidade e realidade que pode ser que ele não tenha. Então em vez de pensar no alternativo como algo distante ou radicalmente separado, eu sempre penso no alternativo como uma forma de alternância que é como uma mudança de fase ou que há um ciclo no tempo e algumas vezes coisas entram em foco como uma alternativa, mas outras vezes exatamente a mesma coisa sai de foco e se parece com o resto do seu entorno. Eu realmente penso nisso meio que em termos de ficção científica, como no Star trek original há essas criaturas que vivem fora de sincronia com a linha do tempo na qual estavam as pessoas do Star trek e às vezes você podia ouvi-las e às vezes não, e por vezes elas entravam na fase e você as via por um minuto e aí elas saíam da fase e eu acho que é mais produtivo pensar o alternativo nesses termos. Então em vez de "o que é o alternativo", eu pergunto “quando é alternativo?”. E podemos fazer com que esses momentos de alternativa ocupem mais e mais do tempo? Em vez de ocupar menos e menos. Como podemos trabalhar para construir um mundo onde há mais tempo para o alternativo.

Você também escreveu sobre filantropia, o setor privado e o Estado. Você poderia compartilhar conosco seu ponto de vista acerca do capitalismo filantrópico e políticas públicas nos Estados Unidos?

Eu me interesso por doações. Eu acho que me interesso por doações porque sou um antropólogo e há Marcel Mauss. Mas eu também me interesso por doações porque vi em primeira mão nas Ilhas Virgens Britânicas a forma como indivíduos de alta renda usavam os paraísos fiscais para estabelecer formas de proteger seus bens sob a forma da criação de trusts filantrópicos. Aí parece haver um movimento bastante cínico. Esse parecer ser o primeiro caso: o movimento cínico de criar uma filantropia falsa no Caribe. Mas ao mesmo tempo todo esse gesto de criar filantropia em um paraíso fiscal ou de tirar vantagem 
da legislação sobre impostos nos Estados Unidos, que permite a dedução para doações filantrópicas, ajuda a entender a forma como dinheiro e moralidade estão sempre interligados. O pano de fundo para os trusts de filantropia caribenhos, mas também para o código de impostos nos Estados Unidos, é que o dinheiro precisa ser purificado, que o dinheiro precisa de uma forma de redenção. É interessante que mesmo a cultura dominante, por assim dizer, mantém essa posição. Há aí as sementes de uma forma de crítica ao capitalismo imbricadas na legislação. Nós sabemos que há algo de errado com dinheiro, sabemos que precisa haver um modo de purificá-lo, sabemos que precisa haver um modo de redimi-lo e vamos colocar isso em nossas políticas públicas. Isso é fascinante, realmente fascinante, essa concessão vinda do capitalismo. Então isso também me interessa. A outra coisa é que mexi bastante no meu trabalho com a ideia de que assim como o alternativo é uma fase temporal, eu mexi bastante com a ideia de que o capitalismo é uma fase temporal que existe simultaneamente com o feudalismo e que há uma série de instituições ganhando espaço no mundo hoje que se parecem e agem muito como o feudalismo. E então eu tenho pensado muito no que acontece quando entidades privadas começam a demandar coisas que se parecem muito com tributos, o que também interfere na capacidade do Estado de cobrar impostos. Então essa espécie de questão imposto versus tributo me interessa muito e a forma como imposto versus tributo também afeta entidades de cunho público versus a proliferação de entidades geradoras de receita privada. Então isso me faz pensar muito. Em parte do trabalho que venho fazendo, mais recentemente, em sistemas e tecnologias de pagamento, venho escrevendo como fornecedores privados de serviços de pagamento se parecem muito com estradas com pedágio ou empresas de rent-seeking que realmente funcionam de acordo com diferentes princípios do que os princípios pelos quais o capitalismo deveria funcionar.

Ao pensar e escrever sobre dinheiro, finanças e economia, muitos antropólogos recorrem à noção de confiança, sendo o sistema monetário um sistema também de confiança. Como você percebe essa noção em relação à crise que se inicia em 2008? Você vê moedas e meios de pagamento alternativos como decorrentes desse cenário?

A questão é que uma série de alternativas antecederam à crise. Apesar de crises e outras desacelerações econômicas parecerem sempre gerar um 
maior interesse em economias alternativas ou em repensar o dinheiro. Não é como se a crise os causasse [moedas e meios de pagamento alternativos], pois eles já estavam lá, eu acho que a crise talvez tenha dado mais espaço a eles. A questão da confiança é interessante para mim porque é quase sempre feita em termos de uma espécie de deslizamento entre confiar em instituições e confiar em indivíduos e meio que prestamos atenção nisso, certo? Pois essa espécie de falta de confiança em moedas emitidas pelo Estado é uma falta de confiança em uma instituição, mas a criação de uma moeda baseada em confiança requer uma confiança nos pares. E confiança entre pares está bem até que algo vá mal. Porque quando algo dá errado, é quando você precisa das suas instituições. Eu sou muito cético quanto a tentativas de criar economias solidárias que esqueçam o lado institucional e eu sempre tento lembrar as pessoas que Estados já fizeram algumas coisas que funcionaram no passado. Podemos pensar nas cooperativas de crédito, podemos pensar em cooperativas institucionalizadas como exemplo, ao invés de correr imediatamente para criar nossa própria economia, com nossa moeda, entre nossos pares. Pois a questão aqui novamente é não há recurso quando algo dá errado, certo? E as únicas instituições que temos que são realmente boas em recursos sem matar pessoas, na maior parte, são os Estados. Eu sei que Estados matam muitas pessoas, então não soa bem... Mas não é como uma briga de socos, há uma corte, há leis. Apesar de o Estado tratar os pobres de forma injusta e apesar de haver pessoas excluídas, ele ainda deveria pelo menos funcionar de acordo com seus princípios e regras internas ao invés de funcionar de acordo com a vontade de indivíduos e eu acho que isso é uma coisa boa.

\section{Que descobertas você destacaria a partir de seu trabalho com mobile money [dinheiro no celular] e Bitcoin, por exemplo, como novas formas de pagamento?}

Algumas descobertas que acho que são bastante importantes têm a ver com como essas coisas, apesar de serem frequentemente democratizantes, podem deixar entrar pela porta dos fundos novas formas de controle através de taxas e tributos. Eu estou muito preocupado com a forma como esses novos sistemas tecnológicos podem estabelecer pontos de trânsito privados para pessoas e dinheiro que tornam mais difícil ou mais caro para as pessoas fazerem coisas que com dinheiro elas podem fazer praticamente de graça. Se eu te 
pago dez dólares, você recebe dez dólares no final, se for em dinheiro, mas se eu enviar dez dólares por meio de uma rede eletrônica, mesmo Bitcoin, alguém vai ficar com um pouco ao longo do caminho. E tudo bem se você estiver recebendo algo em troca, vamos dizer um tempo mais ágil de transação e você quer isso ou uma transação mais segura, isso é algo pelo qual você sabe que está pagando. Mas se você não sabe que está pagando ou não quer esse serviço, então me parece um problema, essa é uma questão. A outra questão que acho muito importante é, seja Bitcoin ou outras moedas alternativas ou dinheiro móvel [por meio de celulares] as pessoas sempre acharão uma forma de fazer as coisas que elas querem fazer com um novo serviço ou uma tecnologia independentemente das intenções dos desenvolvedores ou planejadores. As pessoas sempre colocarão as coisas para seus próprios objetivos e há algo lindo nisso. Volta para a ideia de as pessoas terem seus próprios repertórios monetários, os jogos de dinheiro que querem jogar. Se elas não podem fazer isso com uma tecnologia como o dinheiro móvel, elas vão achar outra forma de fazê-lo ou vão parar de usá-la.

\section{Você usa referência dos estudos de ciência e tecnologia (STS) para abordar isto?}

Sim. Eu fui muito influenciado pelos estudos de ciência e tecnologia. Principalmente pelo trabalho de Latour e Callon e, especialmente, por ambos estarem em diálogo com antropólogos como Marilyn Strathern. Eu acho que Callon em particular realmente ajudou a pensar sobre as formas como as tecnologias de medidas e métricas, distintas formas de ferramentas, distintos compostos de disposições fazem e refazem a coisa que chamamos de mercado e nos ajudou a colocar nossa atenção nessas ferramentas e métricas para entender o mercado em formação.

Como você percebe o campo da antropologia econômica e política nos Estados Unidos?

É estranho nos Estados Unidos, pois por um longo tempo a antropologia econômica ficou trancada no debate formalismo versus substantivismo dos anos 1960. E por um tempo na Sociedade de Antropologia Econômica as forças formalistas e economicistas ganharam e a Sociedade de Antropologia 
Econômica saiu da Associação Americana de Antropologia [AAA]. Costumava ser parte e saiu. Mas agora, nos últimos dois anos, foi reincorporada. E eu acho que, com essa espécie de uma nova geração de pessoas, ela se tornou mais aberta a algumas dessas novas perspectivas. Agora, eu mesmo nunca fui a um encontro da Sociedade de Antropologia Econômica. Isso é interessante. Enquanto isso, a antropologia política nesse país, historicamente, esteve ligada à ideia de que deveria estudar coisas como sistema de parentesco que auxiliavam a mediar disputas em sociedades onde a lei estava ausente. Então, política e leis eram vistas meio que como dois lados da mesma moeda. Eu mesmo fui treinado em antropologia do direito e tive uma série de posições de liderança na Associação de Antropologia Política e do Direito, mas provavelmente sempre me senti muito mais próximo das pessoas do direito do que das pessoas da política. Eu acho que em função do tipo de trabalho que fiz e das redes pelas quais naveguei.

Você poderia nos falar um pouco do seu novo livro How would you like to pay? How technology is changing the future of money?

Esse é um livro novo, ainda não publicado. Eu tentei escrever para um público mais amplo, em primeiro lugar. Em segundo, é cheio de imagens, e tenho muitas fotografias que ilustram as coisas que as pessoas fazem com o dinheiro, além de pagar por coisas. Realmente para chamar a atenção para diversos tipos de relações sociais nos quais o dinheiro é inserido. Coisas como rituais de casamento, como funerais, a forma como dinheiro é utilizado como arte, para fazer declarações políticas, em truques de mágica, e o que eu tento fazer nesse livro é traçar como mudanças tecnológicas estão mudando o dinheiro, mas também dizer que apesar de as tecnologias mudarem o dinheiro, as pessoas ainda vão se engajar com dinheiro da forma como faziam no passado para fazer todas essas coisas sociais, culturais, rituais e religiosas. Basicamente, eu tento dizer que há uma história evolutiva que contamos a nós mesmos sobre o dinheiro, que havia permuta e conchas e o que for, e eu tento dizer “não, essa é a história errada”. Todas essas coisas estavam acontecendo juntas ao mesmo tempo, dinheiro e dádiva estão acontecendo juntos ao mesmo tempo e conforme observamos essa tecnologia se desdobrar, precisamos prestar atenção a todos esses usos sociais que estão acompanhando a mudança do dinheiro. 


\section{Quais são seus maiores interesses atualmente? Em que projetos você está trabalhando?}

Algumas coisas nas quais estou trabalhando são: outro livro com Lana Swartz, uma de minhas colegas, que se formou recentemente pela Universidade do Sul da Califórnia e será professora no próximo ano na Universidade da Virgínia. Lana e eu organizamos uma coletânea intitulada Payment objects: explorations with transactional things, que será publicada pela MIT Press, mas ainda não a finalizamos. Nós reunimos acadêmicos de diversas áreas, bem como alguns profissionais da indústria para escrever pequenos ensaios acerca de objetos de pagamento. Há um ensaio sobre a história dos ATM [caixas eletrônicos]; há um ensaio sobre a história da fita magnética no verso dos cartões de crédito; há um ensaio sobre o leitor do chip dos cartões de débito... Eu escrevi um ensaio sobre pessoas que utilizam o equipamento de assinatura eletrônica para fazer arte, então você vai pagar algo e deve assinar o seu nome, bem, há gente que faz arte naquilo ao invés de assinar e eu realmente refleti sobre a assinatura no ato do pagamento. É um livro divertido e também será bastante ilustrado. Ele deriva de uma espécie de abordagem dos estudos de ciência e tecnologia e comunicação em relação a pagamentos. Basicamente, estamos tentando dizer que as pessoas que estudaram dinheiro apenas olharam para moedas e cédulas e nós precisamos começar a construir um museu dos objetos de pagamento. Então essa é uma coisa. Outra coisa [em que estou trabalhando] é que recentemente comecei outro projeto financiado pela Fundação Nacional de Ciência [NSF] sobre o que acontece com o Bitcoin quando diferentes entidades, corporações, startups, atores privados começam a utilizar a tecnologia subjacente com propósitos legais ao invés de propósitos monetários. Seria um pouco difícil de explicar agora, mas basicamente a tecnologia subjacente ao Bitcoin também permite construir pequenas partes de programação que funcionam como um contrato autoexecutável. Então você e eu concordamos que [por exemplo] em seis anos eu vou te pagar $x$ e nós colocamos isso na tecnologia do Bitcoin. Uma vez que isso está lá, simplesmente acontece. Poderia fazer o saque da sua conta automaticamente. É difícil saber até mesmo o que são essas coisas. Parte do meu argumento é que essas coisas não são contratos porque contratos existem para serem quebrados e essas coisas não podem ser quebradas. Então o que são? Você não pode dizer se está cumprindo ou não, porque haja o que houver, essa pequena máquina vai fazer seu trabalho. Eu estou basicamente tentando entender isso; entender o 
que essas pessoas estão tentando fazer com esses sistemas; entender quais são suas ideias sobre lei e como essa nova tecnologia pode estar mudando a lei. Por fim, isso vem de um interesse na forma como o Bitcoin e sistemas similares reabriram a discussão sobre o que é o dinheiro e acho que agora eles estão prestes a mudar a nossa conversa sobre o que é lei, com potenciais ramificações para desigualdade, basicamente. Então é meio como podemos compreender os processos algorítmicos para fazer leis. É isso que quero tentar fazer.

\section{Você poderia nos falar um pouco sobre o Instituto para Inclusão Financeira, Dinheiro e Tecnologia, que você dirige? Qual é o seu foco, quantas pessoas trabalham com você, financiamentos e expectativas?}

O instituto foi criado em 2008 com um financiamento que recebi da Fundação Bill e Melinda Gates e nossa missão é conduzir pesquisa no Sul global acerca da interação das pessoas com novas tecnologias de pagamento. Especificamente formas móveis e digitais de pagamento. E nós somos uma espécie de choque de realidade nas atividades da Fundação Gates nesses espaços, bem como nos atores da indústria nesses espaços. Porque o que nós fazemos é dar apoio a pesquisadores que são principalmente do Sul global, trabalhando em seus países, que podem observar e ver o que acontece quando algumas dessas novas tecnologias são lançadas lá. Eles estão fazendo, sobretudo, trabalho qualitativo, pesquisa de campo de longo prazo, e como são desses países, eles têm interesse no que está acontecendo. Eles também têm conexões, eles estão incorporados. Eles não são consultores da McKinsey que vêm por uma semana, fazem um survey e pensam que sabem o que está acontecendo. E o que estamos tentando fazer é basicamente trazer essas vozes globais para a discussão, porque elas não têm estado, e assim expandimos a conversa. Também estamos tentando ver com que insights podemos contribuir sobre o real comportamento das pessoas com essas novas tecnologias conforme elas vão se tornando mais comuns. Atualmente, nós financiamos mais de 120 pesquisadores em cerca de 42 ou 43 países. Aqui, na Universidade da Califórnia em Irvine, a equipe que tenho consiste de dois funcionários, duas pesquisadoras de pós-doutorado e comumente de um a três estudantes de pós-graduação, que auxiliam os pesquisadores em campo a fazerem seu trabalho. Também ajudamos a sintetizar as descobertas, disseminá-las, mantemos um blog, auxiliamos os pesquisadores a publicar, essas coisas. 


\section{Referências}

MAURER, B. Mutual life, limited: Islamic banking, alternative currencies, lateral reason. Princeton: Princeton University Press, 2005.

MAURER, B. The anthropology of money. Annual Review of Anthropology, Palo Alto, n. 35, p. 15-36, 2006a.

MAURER, B. Pious property: Islamic mortgages in the United States. New York: Russel Sage Foundation, 2006b.

Recebido em: 06/04/2015

Aprovado em: 02/07/2015 